\title{
On a Result of W.A. Kirk and L.M. Saliga
}

\author{
Milan R. TASKović
}

\begin{abstract}
We prove that a result of Kirk and Saliga [J. Comput. Appl. Math., 113 (2000), 141-152, Theorem 4.2., p. 149] has been for the first time proved before 25 years in Tasković [Publ. Inst. Math., 41 (1980), 249-258, Theorem 1, p. 250]. But the authors neglected and ignored this historical fact.
\end{abstract}

\section{INTRODUCTION}

In recent years a great number of papers have presented generalizations of the well-known Banach-Picard contraction principle.

Recently, Kirk and Saliga have proved the following statement (see [1, Theorem 4.2., p. 149]).

Theorem 1. (Kirk-Saliga [1], Walter [8]). Let $(X, \rho)$ be a complete metric space and suppose $T: X \rightarrow X$ has bounded orbits and satisfies the following condition:

$$
\rho[T x, T y] \leq \Phi\left(\operatorname{diam}\left\{x, y, T x, T y, T^{2} x, T^{2} y, \ldots\right\}\right)
$$

for all $x, y \in X$, where $\Phi: \mathbb{R}_{+}^{0} \rightarrow \mathbb{R}_{+}^{0}:=[0,+\infty)$ is a continuous nondecreasing function and satisfies $\Phi(t)<t$ for every $t>0$. Then $T$ has a unique fixed point $\xi \in X$ and $\left\{T^{n}(a)\right\}_{n \in \mathbb{N}}$ converges to $\xi$ for every $a \in X$.

In connection with this, in 1980 I have proved the following result of fixed point on metric spaces which has a best long of all known sufficiently conditions (linear and nonlinear) for the existing unique fixed point, cf. Tasković [3], [4] and [5].

We notice that the manuscript of [3] was received by the editors January 27 , in 1979 , but published in 1980 . This result generalizes a great number of known results.

In this sense, first, let $(X, \rho)$ be a metric space and $T$ a mapping of $X$ into itself. A metric space $X$ is said to be T-orbitally complete iff every Cauchy sequence which is contained in orbit $O(x)=\left\{x, T x, T^{2} x, \ldots\right\}$ for some $x \in X$ converges in $X$.

2000 Mathematics Subject Classification. Primary: 47H10, Secondary: 54H25.

Key words and phrases. Fixed points, diametral $\varphi$-contractions, complete metric spaces, nonlinear conditions for fixed points, optimization. 
Theorem 2. (Tasković [3]). Let $T$ be a mapping of a metric space $(X, \rho)$ into itself and let $X$ be T-orbitally complete. Suppose that there exists a function $\varphi: \mathbb{R}_{+}^{0} \rightarrow \mathbb{R}_{+}^{0}:=[0,+\infty)$ satisfying

$$
\left(\forall t \in \mathbb{R}_{+}:=(0,+\infty)\right)\left(\varphi(t)<t \text { and } \limsup _{z \rightarrow t+0} \varphi(z)<t\right)
$$

such that

$$
\rho[T x, T y] \leq \varphi\left(\operatorname{diam}\left\{x, y, T x, T y, T^{2} x, T^{2} y, \ldots\right\}\right)
$$

and $\operatorname{diam} O(x) \in \mathbb{R}_{+}^{0}$ for all $x, y \in X$. Then $T$ has a unique fixed point $\xi \in X$ and $\left\{T^{n}(a)\right\}_{n \in \mathbb{N}}$ converges to $\xi$ for every $a \in X$.

A brief first proof of this statement may be found in 1980 from Tasković [3]. Other brief proofs for this we can see in Tasković [4], [5], [6] and [7].

Annotation 1. We notice that Theorem 1 is a very special case of Theorem 2. Indeed, since $\Phi: \mathbb{R}_{+}^{0} \rightarrow \mathbb{R}_{+}^{0}$ of Theorem 1 satisfy all required hypothesis $(\mathrm{I} \varphi)$ for the function $\varphi: \mathbb{R}_{+}^{0} \rightarrow \mathbb{R}_{+}^{0}$ in Theorem 2 (other conditions are equal, an example $(\mathrm{K})$ and $(\mathrm{A})$ and completeness), directly applying Theorem 2 we obtain Theorem 1.

Annotation 2. De facto, in [3] I have introduced the concept of a diametral $\varphi$-contraction $T$ of a metric space $(X, \rho)$ into itself, i.e., there exists a function $\varphi: \mathbb{R}_{+}^{0} \rightarrow \mathbb{R}_{+}^{0}$ satisfying $(\mathrm{I} \varphi)$ and $(\mathrm{A})$.

Annotation 3. In the preceding sense, since the function $\Phi: \mathbb{R}_{+}^{0} \rightarrow \mathbb{R}_{+}^{0}$ (in Theorem 1) is continuous nondecreasing and satisfies $\Phi(t)<t$ for every $t>0$, we directly obtain that the conditions $(\mathrm{I} \varphi)$ in Theorem 2 hold. Thus we directly obtain Theorem 1 .

Annotation 4. The main part of the first written proof of Theorem 2 (on diametral $\varphi$-contractions) may be found in 1978 as a frame for general convergence of real sequences. The proof of Theorem 2 is based upon the following fundamental lemma in 1978.

Lemma 1. (Tasković [2]). Let the mapping $\varphi: \mathbb{R}_{+}^{0} \rightarrow \mathbb{R}_{+}^{0}$ have the property $(\mathrm{I} \varphi)$. If the sequence $\left(x_{n}\right)$ of nonnegative real numbers satisfies the condition of the form

$$
x_{n+1} \leq \varphi\left(x_{n}\right), \text { for } n \in \mathbb{N},
$$

then the sequence $\left(x_{n}\right)$ tends to zero. The velocity of this convergence is not necessarily geometrical.

We notice that the manuscript [2] was received by the editors on October 15, 1975, but published in 1978 .

\section{REFERENCES}

[1] W. A. Kirk and L. M. Saliga, Some results on existence and approximation in metric fixed point theory, J. Comput. Appl. Math., 113 (2000), 141-152.

[2] M. R. Tasković, A generalization of Banach's contraction principle, Publ. Inst. Math. 37 (1978), 179-191. 
[3] M.R. Tasković, Some results in the fixed point theory-II, Publ. Inst, Math., 41 (1980), 249-258.

[4] M.R. Tasković, Some theorems on fixed point and its applications, Annal. Soc. Math. Polonae, Series I, Comm. Math. 24 (1984), 323-334.

[5] M.R. Tasković, Some new principles in fixed point theory, Math. Japonica, 35 (1990), 645-666.

[6] M.R. Tasković, Nonlinear Functional Analysis, Second Book, Monographs - Global Convex Analysis: General convexity, Variational methods and Optimization, Zavod za udžbenike i nastavna sredstva and Vojnoizdavački zavod, Beograd, 2001, (In Serbian), 1223 pages. English summary: Transversal and fixed points, forks, general convex functions and applications, Vol. 2 (2001), 1067-1172.

[7] M.R. Tasković, Theory of transversal point, spaces and forks, Monographs of a new theory, Beograd 2005, 1054 pages, VIZ-Beograd.

[8] W. Walter, Remarks on a paper by F. Browder about contractions, Nonlinear Anal., TMA, 5 (1981), 21-25.

Milan R. TASKOviĆ

Faculty of Mathematics

11000 Belgrade, P.O. Box 550

SERBIA

Home Address:

Milan R. Tasković

Nehruova 236

11070 BELGRADE

SERBIA

E-mail address: andreja@predrag.us 